\title{
ANCORAGEM PSICOSSOCIAL A PARTIR DOS SENTIMENTOS NEGATIVAMENTE VALORADOS: REPRESENTAÇÕES SOCIAIS DE CIGANOS
}

\author{
PSYCHOSOCIAL ANCHORAGE BASED ON NEGATIVELY VALUED FEELINGS: SOCIAL \\ REPRESENTATIONS OF GYPSIES
} ANCLAJE PSICOSOCIAL A PARTIR DE LOS SENTIMIENTOS NEGATIVAMENTE VALORADOS:
REPRESENTACIONES SOCIALES DE GITANOS

\author{
Julia Alves Brasil \\ Mariana Bonomo ${ }^{* *}$ \\ Amandha Gyselle Martins Nascimento ${ }^{* * *}$ \\ André Mota Livramento ${ }^{* * * *}$ \\ Lidio de Souza (in memoriam) (**** $^{*}$
}

\begin{abstract}
RESUMO
Tendo como referência a abordagem não consensual da teoria das representaçôes sociais, este trabalho teve como objetivo investigar como se articulam as representações sociais e a dimensão afetiva associadas ao objeto social "ciganos", entre população não cigana da Grande Vitória-ES. Foram desenvolvidos dois estudos complementares com (1) 108 estudantes universitários e (2) 10 sujeitos que associaram sentimentos de valoração negativa aos ciganos. A coleta dos dados foi realizada por meio da aplicação de questionário e de entrevista em profundidade, e o tratamento das informações obtidas foi conduzido com o auxílio dos softwares SPAD-T e Alceste. Os resultados indicaram a (re)produção de estereótipos negativos vinculados aos ciganos e a dimensão afetiva fortemente marcada por medo e aversão, núcleo de preconceito e discriminação contra os ciganos.
\end{abstract}

\footnotetext{
Texto recebido em 16 de abril de 2015 e aprovado para publicação em 15 de setembro de 2016.

*Doutora em Estudos Culturais, na especialidade de Comunicação e Cultura, pela Universidade do Minho, Portugal. Mestrado e graduação em Psicologia pela Universidade Federal do Espírito Santo (UFES). Atualmente é pesquisadora de pós-doutorado no Programa de Pós-Graduação em Psicologia da UFES. E-mail: juliaalvesbrasil@gmail.com.

**Doutora em Psicologia (2010) pela UFES, com trabalhos vinculados à Psicologia social, professora do Departamento de Psicologia Social e do Desenvolvimento e do Programa de Pós-Graduação em Psicologia da UFES, membro do GT/ANPEPP Memória, Identidade e Representações Sociais e pesquisadora da Rede de Estudos e Pesquisas em Psicologia Social (RedePSO - UFES).E-mail: marianadalbo@gmail.com.

***Bacharel em Psicologia pela UFES, atua como psicóloga no Centro de Integração Empresa-Escola do Espírito Santo. E-mail: amandhag@hotmail.com.

****Mestre em Psicologia pelo Programa de Pós-Graduação em Psicologia da UFES, especialista em Terapia CognitivoComportamental (Unifia/Capacitar), graduado em Psicologia pela UFES. Tem experiência com pesquisas científicas nas áreas de Psicologia Social, Psicologia Escolar e Saúde Mental. Atualmente é Psicólogo do Instituto Federal do Espírito Santo - Nova Venécia e docente do curso de Psicologia da Faculdade Multivix, também em Nova Venécia. E-mail: drepsi@yahoo.com.br.

*****Pós-doutor e doutor em Psicologia Social pela Universidade de São Paulo (USP), mestre em Psicologia Social pela Pontifícia Universidade Católica de São Paulo, professor associado III, atuando no Programa de Pós-Graduação em Psicologia e no Departamento de Psicologia Social e do Desenvolvimento da UFES. E-mail: marianadalbo@gmail.com.
} 
Palavras-chave: Ciganos. Estereótipos. Representaçôes sociais. Sentimentos.

\begin{abstract}
Having as a reference the non-consensual approach of the Theory of Social Representations, this study aimed to investigate how the social representations and the affective dimension associated with the social object "Gypsies" among non-Gypsy population within the metropolitan area of Vitória-ES. Two complementary studies were developed with (1) 108 college students and (2) 10 subjects who linked feelings of negative assessment towards the Gypsies. Data collection was performed by applying a questionnaire and in-depth interview and the handling of the obtained information was processed with the help of SPAD-T and Alceste softwares. The results showed the (re)production of negative stereotypes linked to Gypsies and the affective dimension strongly marked by fear and aversion, core of prejudice and discrimination against Gypsies.
\end{abstract}

Keywords: Gypsies. Stereotypes. Social representations. Feelings.

\title{
RESUMEN
}

En este trabajo se analizan las relaciones sociales y la dimensión afectiva asociadas al objeto social "gitanos", entre población no gitana de la Gran Victoria-ES, teniendo como referencia el abordaje no consensuado de la Teoría de las Representaciones Sociales. Dos estudios complementarios fueron desarrollados con (1) 108 estudiantes universitarios y (2) 10 sujetos que asociaron sentimientos de valoración negativa a los gitanos. La recolección de los datos fue realizada por medio de la aplicación de cuestionario y de entrevista en profundidad y el tratamiento de las informaciones obtenidas fue conducido con la ayuda del software SPAD-T y Alceste. Los resultados indicaron la (re) producción de estereotipos negativos vinculados con los gitanos y la dimensión afectiva fuertemente marcada por miedo y aversión, núcleo de prejuicio y discriminación contra los gitanos.

Palabras clave: Gitanos. Estereotipos. Representaciones sociales. Sentimientos.

\section{INTRODUÇÃO}

diversidade ou pluralidade cultural, constituída a partir da existência de
diferentes grupos sociais, apresenta-se como um dos grandes desafios
do mundo contemporâneo, exigindo dos grupos humanos valores que
favoreçam o diálogo e o respeito à diferença (Rezende, 2000). Embora a
necessidade de categorizar o "outro" surja como condição inerente à própria 
dinâmica social e constituição da realidade, o que tornaria ainda mais desafiador o projeto de construção de sociedades solidárias (Souza, 2004), a reflexão sobre os processos de construção do "outro" como diferente bem como a produção de estereótipos que criem e fortaleçam espaços de discriminação entre grupos sociais podem contribuir para se discutirem a segregação e a violência sofridas secularmente pelos ciganos.

Apesar do termo universal utilizado, Moonen (2008) informa que ciganos e ciganólogos convencionaram a divisão dos ciganos em três largos distintos seguimentos: os sinti, que falam a língua sintó, residentes principalmente na Alemanha, Itália e França; os rom, que falam a língua romani e estão predominantemente nos países dos Bálcãs e nas Américas; e os calón (ciganos ibéricos), que falam caló e habitam Portugal e Espanha, além de países da Europa e da América do Sul. Segundo Sibar (2012), os calon foram o primeiro grupo a migrar para o Brasil, no século XVI, e residem até os dias de hoje, em sua maioria, em situações precárias, à margem da sociedade. Além dessa etnia, os rom também habitam o território nacional, configurando-se num grupo de maior visibilidade em comparação ao primeiro, pois, de acordo com Moonen (2008), os rom habitualmente consideram-se "ciganos autênticos" e classificam os outros como "ciganos espúrios". Apesar das peculiaridades de cada grupo, Moscovici (2009) chama atenção para um denominador comum a todos os grupos ciganos: o histórico de perseguiçôes, ódio e discriminação sofridos ao longo de muitos séculos, por onde estiveram.

Sobre essa condição de marginalização social dos ciganos, Ferrari (2002, p. 20) informa que, "Se o Ocidente se viu obrigado a se relacionar com os ciganos, foi também inevitável a formação de conceitos sobre eles, que variam ligeiramente nos países da Europa e da América". Associados a conceitos fundamentados em estereótipos negativos, atos de "anticiganismo" são recorrentes há muitos séculos, em diferentes contextos e nacionalidades. De acordo com Moonen (2008), o anticiganismo pode ser compreendido como atitudes ou "doutrinas" hostis, execução de medidas discriminatórias contra ciganos, atos ou políticas contrárias aos interesses e direitos destes, como casos já constatados de escravidão, prisão, deportação, isolamento, integração e genocídio.

No Brasil, segundo Teixeira (2008), a reduzida bibliografia produzida acerca dos ciganos pode ter favorecido o aparecimento de lendas e crendices a respeito desses povos, que, para Moonen (2011), "Constituem a minoria étnica menos conhecida, e, talvez por isso, mais odiada e discriminada do Brasil" (p. 5). A documentação oficial acerca da história dos ciganos em território nacional data de 1574, "quando o cigano João Torres, sua mulher e filhos foram degredados para o Brasil. Em Minas Gerais, a presença cigana é nitidamente notada a partir 
de 1718, quando chegam ciganos vindos da Bahia, para onde haviam sido deportados de Portugal" (Teixeira, 2008, p. 5). Os relatos e descrições referentes aos ciganos no tempo da colonização brasileira, de acordo com Teixeira (2008), parecem não diferir de elementos ainda hoje encontrados no imaginário social: "Os ciganos nas cidades mineiras estavam em dissonância aos ideais de civilização e progresso [...] São identificados como elementos incivilizáveis, inúteis à sociedade, [...] vândalos, enfim, uma anomalia social e racial" (p. 5).

Acton e Mundy (1997), no campo da Sociologia, consideram a "supergeneralização" uma falha constatada na literatura acadêmica referente aos ciganos, pois "observadores têm sido levados a acreditar que práticas de grupos particulares são universais" (p. 89). Esses trabalhos favorecem a construção simbólica de uma ideia fixa do que é ser cigano, que, segundo Rezende (2000), ao desconsiderar a diversidade de grupos e modos de vida, acaba por reforçar o preconceito que acompanha as imagens de um povo sempre estrangeiro e pertencente a lugar algum. Miranda (2011) conclui que, a partir da "história dos ciganos", escrita por não ciganos, pode-se compreender as imagens e histórias formadas por não ciganos e não sobre os "ciganos em si"; pode-se dizer, na realidade, que seria uma "história das representações dos ciganos".

O estudo realizado por Ferrari (2002), que investigou a formação do imaginário ocidental acerca dos ciganos, baseado na análise das representações mais recorrentes nas obras literárias brasileiras e europeias, reforça o argumento apresentado por Miranda (2011) e Rezende (2000). Entre as mais citadas, constam do roubo de crianças, a compra e venda de cavalos, as adivinhaçóes e os espetáculos de músicas e danças. A autora salienta que a literatura expõe o que se imagina a respeito dos ciganos, sem o compromisso de retratar suas reais condições de vida, especialmente no que se refere a informações que poderiam contribuir para se discutir a necessidade de elaboração de políticas públicas próciganas.

Apoiando-se nas reflexões de Alexandre (2003), é possível constatar que a imagem dos ciganos se fundamenta em construçôes sociais que se configuram como sistema de crenças, com reflexos claros na produção e disseminação de estereótipos estigmatizantes acerca do grupo. Dessa forma, "É fundamental se interrogar sobre a origem destas imagens sociais, ideologicamente motivadas, por que elas perduram e são produzidas, e, por fim, como vêm sendo (ou devem ser) questionadas e rechaçadas" (Freire Filho, 2004, p. 65), questóes que podem encontrar apoio analítico na teoria das representaçôes sociais, aporte teórico adotado como referência para o desenvolvimento deste trabalho. 


\section{REPRESENTAÇÕES SOCIAIS E DIMENSÃO AFETIVA}

A teoria das representações sociais, proposta por Moscovici, em 1961, deu início a um novo campo de investigação no universo da Psicologia social. A partir da chamada "grande teoria", três abordagens complementares foram se desenvolvendo com diferentes arranjos metodológicos e conceituais:

a) Denise Jodelet apresentou trabalhos mais fiéis à teoria original;

b) Jean-Claude Abric enfatizou a dimensão cognitiva e elaborou a teoria do núcleo central; e

c) Willem Doise associou à teoria um enfoque mais sociológico (Sá, 1998), propondo a abordagem não consensual, utilizada como referência no desenvolvimento do presente estudo.

Na concepção de Doise, Clemence e Lorenzi-Cioldi (1995), as representações sociais são "princípios organizadores das variaçôes na tomada de posição dos diferentes indivíduos" (p. 11). Pereira, Torres e Almeida (2003) destacam que a variabilidade das representaçôes seria a noção central do conceito proposto por Doise (1992), apresentando-se como interessante aporte teórico para a condução das reflexões propostas nesse trabalho, posto que permite focalizar a investigação dos processos que organizam as representaçôes sociais de "ciganos" a partir das diferentes inserções dos sujeitos da representação. Operacionalizando o conceito, Doise (1992) propôs três possíveis formas de ancoragem:

a) psicológica, pautada nos valores e crenças individuais;

b) sociológica, indica de que maneira a pertença a diferentes grupos influencia na formação do campo representacional; e

c) psicossociológica, que se fundamenta em discursos ideológicos e na natureza das relações sociais.

Segundo Guareschi e Jovchelovitch (2008), é na tensão entre o coletivo e o individual que as representaçôes sociais se constituem e ganham sentido. Por meio delas, evidenciam-se ações e tomadas de posição dos indivíduos e grupos sociais diante dos diversos objetos sociais. Dois seriam os processos basilares de sua formação e dinâmica: a "objetivação" e a "ancoragem". A objetivação "faz com que se torne real um esquema conceitual, com que se dê a uma imagem; uma contrapartida material" (Moscovici, 1978, p. 110). À ancoragem, por sua vez, de acordo com Araújo (2008), cabe a função de associar, a partir de semelhanças, o novo, que é estranho ao grupo, às representaçóes já existentes. O estudo das 
representaçôes sociais seria um dos caminhos para compreender as práticas sociais e a dinâmica das interações sociais, bem como a própria constituição da realidade social, manifestando as ambiguidades e contradiçôes da vida social. Como "oposições relacionais de base" (Marková, 2006), os thematas contribuem para a compreensão do processo de elaboração das representações sociais com base nesse campo de antinomias (Moscovici, 1992, 2003), posto que consistem em: "unidade semântica de base presente no pensamento do senso comum, exprimindo uma oposição [...]. Os thematas estão enraizados na cultura e são transmitidos pela linguagem, pela comunicação e pelo senso comum de geração em geração" (Marková, 2003, p. 234).

Dimensão ainda negligenciada no estudo das representações sociais, o campo afetivo constitui uma das mais importantes dimensões do fenômeno representacional (Arruda, 2009a; Arruda \& Pombo-de-Barros, 2010; Campos \& Rouquette, 2003). De acordo com Arruda (2009b), o significado associado aos objetos sociais é ativado a partir de "um fluxo de afetos, imaginários, estilos cognitivos e se configura por meio de processos que, sendo sociais, são ao mesmo tempo psicológicos" (p. 742). Para Arruda e Pombo-de-Barros (2010), pode-se relacionar os processos afetivos com a necessidade de afastamento do indivíduo diante de situações que possam ameaçar a própria identidade ou a do grupo social com o qual se identifica. Para a manutenção desse sistema, diante da presença do novo e do diferente, recorre-se às representaçôes para a construção de significados que protejam o grupo, o que pode resultar em processos de discriminação social e estigmatização do "outro", questão que se aplica aos ciganos, objeto de estudo deste trabalho.

Referenciado pelo aporte teórico-conceitual das representações sociais, este estudo tem como objetivo investigar como se articulam a dimensão afetiva e o campo representacional a partir da tomada de posição de indivíduos não ciganos diante do objeto de representação social "ciganos". A identificação dos processos e conteúdos constitutivos do campo representacional não cigano acerca dos ciganos apresenta-se como recurso estratégico à compreensão das práticas sociais que se tem direcionado a essa categoria social.

\section{MÉTODO}

Tendo em vista os objetivos apresentados, optou-se pelo desenvolvimento de dois estudos, articulados de maneira complementar, como estratégia para investigação das questôes propostas. 


\subsection{Estudo 1: representaçóes sociais e dinâmica afetiva associadas aos ciganos}

\subsubsection{Participantes e procedimento de coleta dos dados}

Inicialmente, foram aplicados 300 questionários em estudantes de ensino superior público e privado da Grande Vitória, Estado do Espírito Santo. A aplicação do instrumento, com duração de aproximadamente 40 minutos, ocorreu durante as aulas da graduação das seguintes áreas de conhecimento: Ciências Humanas, Naturais, Sociais, Exatas e da Saúde. Do número total de respondentes, foram selecionados os questionários dos estudantes que se dispuseram a participar da segunda etapa da pesquisa. Dessa forma, para realização do estudo 1, participaram 108 estudantes, com idades entre 18 e 35 anos, sendo $65 \%$ do sexo feminino.

\subsubsection{Instrumento e tratamento de dados}

$\mathrm{O}$ instrumento era composto pelas seguintes seçōes: associação livre para o termo indutor "ciganos"; questão fechada múltipla sobre posicionamento afetivo em relação aos ciganos, em uma lista com 26 itens (13 sentimentos positivos; 13 sentimentos negativos); dados socioeconômicos (sexo, religião, etnia, escolaridade e cidade de origem); e informaçóes para contato com os potenciais participantes para o estudo 2 .

Como recurso para tratamento dos dados, utilizou-se o software SPAD-T (Lebart, Morineau, Becue, \& Haeusler, 1994) que, por meio da análise de cluster, possibilitou a identificação de grupos de sujeitos em função das representações e dos sentimentos mais característicos associados aos ciganos.

\subsection{Estudo 2: ancoragem psicossocial a partir dos sentimentos negativamente valorados}

\subsubsection{Participantes e procedimento de coleta dos dados}

Tendo em vista o objetivo deste estudo, foram selecionados 27 sujeitos, agrupados a partir da análise de cluster processada no estudo 1, que apresentaram tomada de posição afetiva negativa em relação aos ciganos. Desses potenciais respondentes, foram entrevistados 10 sujeitos, com idades entre 19 e 47 anos, igualmente distribuídos entre homens e mulheres, que se disponibilizaram a participar do estudo. 
Para a realização das entrevistas, os participantes foram contatados para convite e agendamento, conforme disponibilidade de horário, data e local escolhidos em comum acordo entre o pesquisador e o entrevistado. As entrevistas, individualmente realizadas, foram gravadas com o consentimento dos participantes, formalmente registrado por meio do termo de consentimento livre e esclarecido para participação em pesquisas.

\subsubsection{Instrumento e procedimento de organização dos dados}

As entrevistas foram conduzidas tendo como referência um roteiro semiestruturado, composto por questôes abertas, cujo objetivo era o de aprofundar as questôes relativas às representaçôes sociais de ciganos e sua dimensão afetiva, bem como as experiências de contato com o grupo cigano. Após a transcrição das entrevistas e montagem do corpus de dados, as narrativas foram processadas por meio do software ALCESTE (Analyse Lexicale par Contexte d'un Ensemble de Segments de Texte) (Reinert, 1990), tendo sido utilizado o recurso de análise da classificação hierárquica descendente, que permite observar a disposição das diferentes classes produzidas na análise, compostas por elementos que se agrupam em função de sua coocorrência e semelhança lexical (Camargo, 2005; Oliveira, Gomes, \& Marques, 2005).

\section{RESULTADOS}

\subsection{Estudo 1: representaçôes sociais e dinâmica afetiva associadas aos ciganos}

No estudo 1, constatamos que a maioria dos participantes já teve contato visual com ciganos, ou seja, 103 sujeitos mencionaram terem visto ciganos em algum lugar (presencialmente ou pelos meios de comunicação). As demais formas de contato investigadas se configuraram como menos frequentes: 38 participantes mencionaram já terem estabelecido algum tipo de conversa com um(a) cigano(a) (geralmente, em situações de abordagem na rua para leitura de mão); 9 realizaram algum negócio com eles; e apenas 3 participantes disseram já ter tido amizade com membros dessa etnia.

As informações referentes ao contato podem indicar que as representações sobre os ciganos, analisadas neste estudo, não advêm de um conhecimento elaborado com base no contato direto com o objeto, mas sejam produzidas por meio de diferentes canais de comunicação social, fortemente vinculados ao pensamento 
social hegemônico. Na tabela 1, é apresentado o conteúdo das representações captadas a partir das associações livres para o temo indutor "ciganos". Foram selecionados os agrupamentos de evocações que contabilizaram frequência igual ou superior a 6 .

Tabela 1. Elementos característicos da representação social de ciganos

\begin{tabular}{lclc}
\hline \multicolumn{1}{c}{$\begin{array}{c}\text { Elementos de } \\
\text { Representaçóes }\end{array}$} & Frequência & \multicolumn{1}{c}{$\begin{array}{c}\text { Elementos de } \\
\text { Representaçóes }\end{array}$} & Frequência \\
\hline Nômades & 76 & Marginalizados & 9 \\
Vestimentas e adereços & 41 & Família & 8 \\
Cultura & 34 & Pedintes & 7 \\
Misticismo & 30 & Diferentes & 7 \\
Leitura de mão & 24 & Negociam & 7 \\
Enganam & 23 & Preguiçosos & 6 \\
Ouro & 18 & Sem emprego fixo & 6 \\
Acampamento & 17 & Liberdade & 6 \\
Sujos & 16 & Etnocentrismo & 6 \\
Dança e música & 16 & Alegria & 6 \\
Posses/dinheiro & 13 & Incomodam & 6 \\
Barracas & 12 & & \\
\hline
\end{tabular}

Fonte: elaborado pelos autores.

De acordo com os dados apresentados, foram mencionados elementos representacionais com aspectos mais descritivos do objeto estudado, como "vestimentas", "adereços", "ouro" (relacionados ao indivíduo), "acampamentos" e "barracas" (referentes à moradia cigana), aspetos ligados a crenças e misticismo (leitura de mão), bem como elementos que denotam a constituição de uma imagem dos ciganos como livres e sem referência territorial ("liberdade" e "nômades"). Termos como "cultura" e "diferentes" podem caracterizar a constituição de dimensões da representação que estabelecem marcadores entre ciganos e não ciganos, campo de significação que se constitui como distintivo e valorado negativamente quando ressaltados os estereótipos de "preguiçosos", "enganam" e "sujos".

No que se refere aos sentimentos associados aos ciganos, como é possível constatar na tabela 2, entre os mais frequentemente mencionados, destacamse tanto elementos positivamente valorados ("curiosidade", "respeito", "solidariedade", "admiração" e "encantamento"), quanto sentimentos que indicam a face negativa das representações identificadas ("insegurança”, "desconfiança”, "indiferença”, "medo" e "mal-estar"). 
Tabela 2. Distribuição das frequências absolutas do campo afetivo associado aos ciganos

\begin{tabular}{lclc}
\hline \multicolumn{1}{c}{ Sentimentos } & Frequência & \multicolumn{1}{c}{ Sentimentos } & Frequência \\
\hline Curiosidade (+) & 84 & $\begin{array}{l}\text { Tranquilidade } \\
(+)\end{array}$ & 18 \\
Insegurança (-) & 66 & Nojo (-) & 17 \\
Desconfiança (-) & 66 & Simpatia (+) & 16 \\
Respeito (+) & 60 & Aversão (-) & 15 \\
Indiferença (-) & 33 & Tristeza (-) & 13 \\
Solidariedade (+) & 28 & Empatia (+) & 10 \\
Admiração (+) & 25 & Alegria (+) & 9 \\
Encantamento (+) & 24 & Afeição (+) & 8 \\
Medo (-) & 23 & Antipatia (-) & 8 \\
Mal-estar (-) & 20 & Desprezo (-) & 5 \\
\hline
\end{tabular}

Fonte: elaborado pelos autores.

Procedeu-se a formação de clusters (agrupamentos) de sujeitos em relação ao conteúdo mais característico dos sentimentos analisados. Foram identificados os seguintes grupos:

a) sentimentos positivos (18 sujeitos): tranquilidade, afeição, admiração, empatia e simpatia;

b) sentimentos negativos (27 sujeitos): mal-estar, aversão, antipatia, medo, desprezo e nojo; e

c) sentimentos positivos e negativos, simultaneamente (63 sujeitos): indiferença, curiosidade e solidariedade.

No plano fatorial (figura 1), são projetados os elementos constituintes do campo representacional associados aos clusters de sujeitos identificados a partir da dimensão afetiva. Informamos que o terceiro cluster não apresentou associação significativa ao campo representacional de "ciganos", segundo a disposição dos fatores identificados, e, por isso, não foi projetado. 
Figura 1. Análise fatorial de correspondência: plano fatorial referente ao campo representacional para o termo indutor "ciganos

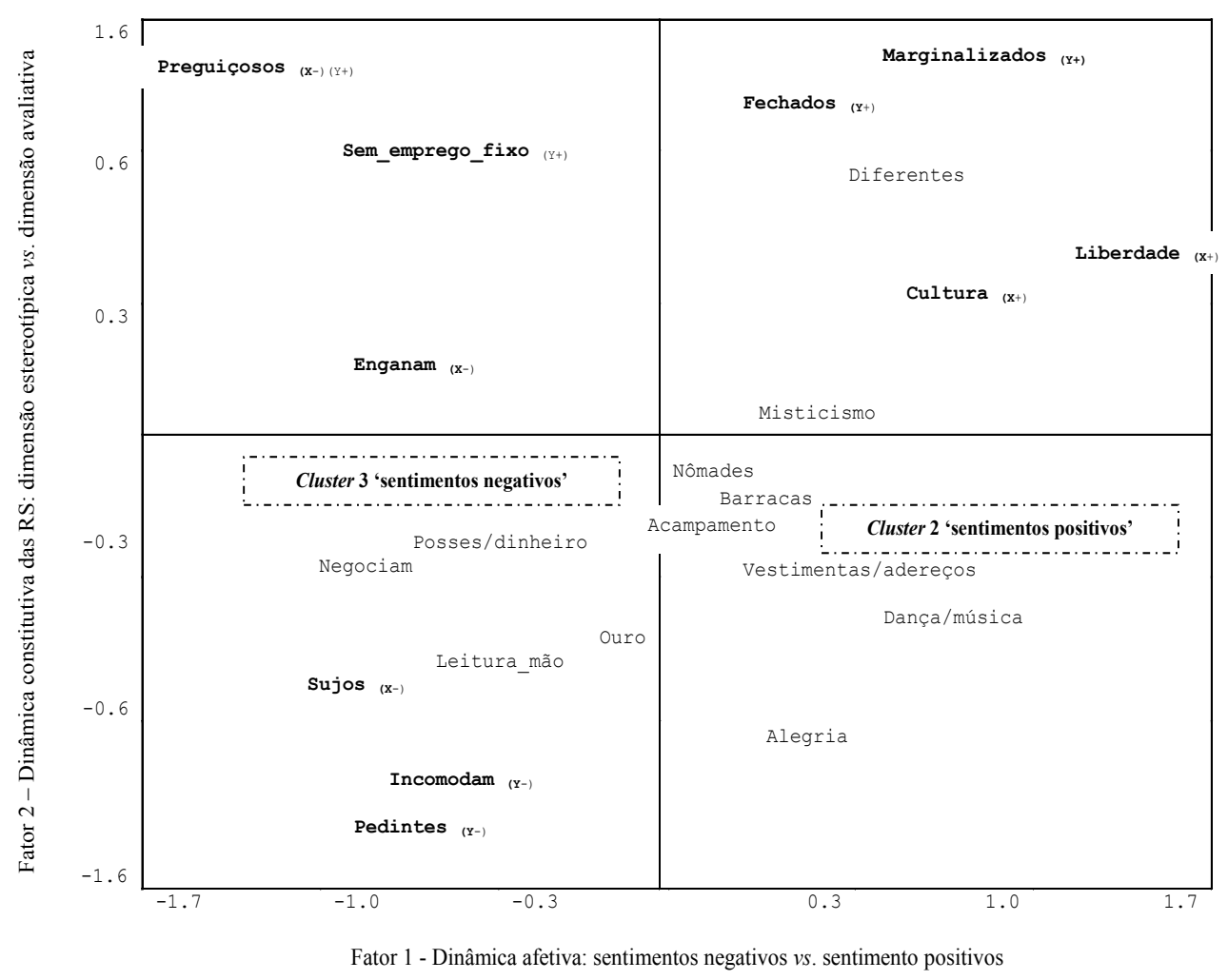

Fonte: elaborado pelos autores.

Nota: A fim de identificar os elementos que contribuíram significativamente à composição dos eixos, assumiu-se c.a. (contributo absoluto) $=100 / n$, sendo $n=20$ (número de elementos que constituíram o campo representacional); logo, c.a. $\geq 5.0$. Os elementos significativos foram destacados a partir do sinal $\left(x^{-}\right),\left(x^{+}\right),\left(y^{-}\right)$e $\left(y^{+}\right)$, de acordo com sua respectiva localização no plano fatorial.

Como princípios organizadores das representaçôes sociais de ciganos, foram identificados os seguintes fatores:

fator 1: dimensão afetiva (composto pelos polos "sentimentos negativos" versus "sentimentos positivos"); e

fator 2: dinâmica constitutiva das representações sociais (formado pelos polos "dimensão estereotípica" versus "dimensão avaliativa").

No fator 1, os termos projetados no polo negativo $\left(\mathrm{x}^{-}\right)$, em contraste ao polo positivo $\left(\mathrm{x}^{+}\right)$, denotam oposição entre os posicionamentos afetivos e relação aos ciganos. No que tange ao polo negativo, associados ao cluster sentimentos negativos, constam dos seguintes elementos de representação: preguiçosos, sem emprego fixo, enganam, posses/dinheiro, negociam, sujos, ouro, leitura de mão, incomodam e pedintes. Esse conjunto de dados sugere a constituição de um campo 
semântico compartilhado por sujeitos do cluster sentimentos negativos, conteúdo que pode estar mais próximo da (re)produção de preconceito e de discriminação social. $\mathrm{O}$ agrupamento associado aos sentimentos positivos (cluster sentimentos positivos), por sua vez, também revela a presença de estereótipos, porém se trata de representações mais romantizadas e descritivas, as quais ressaltam a diferença cultural (cultura, fechados e diferentes), a dimensão mística (misticismo), certas peculiaridades do grupo (nômades, barracas e acampamentos), crítica em relação à exclusão sofrida pelos ciganos (marginalizados) e a ideia de que são um povo livre e alegre (liberdade, alegria, danças e músicas), que se veste de maneira diferente (vestimentas e adereços).

Organizando os significados que compõem o fator 2 , a dinâmica constitutiva das representações sociais sugere a formação de polos opostos em função da natureza de seu conteúdo mais característico. $\mathrm{Na}$ "dimensão avaliativa" estão presentes termos como "diferentes" e "fechados", que denotam a comparação entre as "culturas" cigana e não cigana, também associada ao universo místico e à ideia de liberdade. Elementos como "sem emprego fixo" e "preguiçosos", e a concepção de que os ciganos "ganham a vida enganando as pessoas", traduzem essa dinâmica de posição avaliativa que compara os modos de vida cigano e não cigano, segundo as referências dos respondentes. O elemento "marginalizado", por sua vez, destaca o processo de exclusão a que têm sido submetidos e a condição de pobreza em que se encontra grande parte dos grupos ciganos, podendo revelar uma dimensão mais crítica da avaliação empreendida. $\mathrm{Na}$ "dimensão estereotípica”, aparecem expressões que descrevem os ciganos a partir do contato com não ciganos (pedintes, incomodam e sujos), além de elementos que fazem referência aos trajes típicos (vestimentas e adereços), à ideia de que são ricos (negociam, ouro e posses/dinheiro), ao nomadismo (barracas e nômades) e à quiromancia (leitura de mão), bem como à "dança" e à "música" que contribuem para a composição da imagem dos ciganos como povo "alegre".

A partir da dimensão afetiva identificada nesse primeiro estudo, propôs-se o desenvolvimento de um estudo qualitativo e complementar com indivíduos do cluster sentimentos negativos, tendo em vista a necessidade e importância de conhecer mais detalhadamente a dinâmica de constituição dos estereótipos valorados negativamente, geralmente associados a medo, aversão e mal-estar, como constatado no estudo 1 .

\subsection{Estudo 2: ancoragem psicossocial a partir dos sentimentos negativamente valorados}

O estudo 2 teve a participação de 10 estudantes universitários selecionados a partir do cluster "sentimentos negativos", identificado no estudo 1. No que 
tange ao nível de contato relatado pelos entrevistados em relação aos ciganos, este basicamente se refere ao contato visual (presencialmente ou pelos meios de comunicação) e a rápidas conversas durante abordagem de rua (geralmente, para leitura de mão, condição que era prontamente rejeitada pelos participantes do estudo).

$\mathrm{Na}$ tabela 3, são apresentados os termos evocados e os sentimentos associados aos ciganos pelos sujeitos pertencentes ao "grupo sentimentos negativos" (27) do estudo 1 e pelos participantes do estudo 2 (10).

Tabela 3. Termos evocados e sentimentos associados aos ciganos (sujeitos do cluster sentimentos negativos)

\begin{tabular}{|c|c|c|c|c|c|c|c|}
\hline \multicolumn{4}{|c|}{ Termos evocados - objeto ciganos } & \multicolumn{4}{|c|}{ Sentimentos associados aos ciganos } \\
\hline \multicolumn{2}{|c|}{ Estudo $1(n=27)$} & \multicolumn{2}{|c|}{ Estudo $2(n=10)$} & \multicolumn{2}{|c|}{ Estudo $1(n=27)$} & \multicolumn{2}{|c|}{ Estudo $2(n=10)$} \\
\hline $\begin{array}{l}\text { Termo } \\
\text { evocado }\end{array}$ & ${ }^{*} \mathrm{~F}$. & \begin{tabular}{|l|} 
Termo \\
evocado
\end{tabular} & ${ }^{*} \mathrm{~F}$. & Sentimentos & ${ }^{*} \mathrm{~F}$. & Sentimentos & ${ }^{*} \mathrm{~F}$. \\
\hline Nômades & 15 & Enganam & 6 & Desconfiança & 24 & Desconfiança & 9 \\
\hline Enganam & 12 & Nômades & 6 & Insegurança & 23 & Mal-estar & 8 \\
\hline $\begin{array}{l}\text { Vestimentas/ } \\
\text { adereços }\end{array}$ & 10 & Ladrão & 3 & Mal-estar & 20 & Insegurança & 7 \\
\hline Sujos & 6 & Incomodam & 2 & Medo & 15 & Aversão & 5 \\
\hline Ouro & 6 & $\begin{array}{l}\text { Leitura de } \\
\text { mão }\end{array}$ & 2 & Aversão & 14 & Curiosidade & 4 \\
\hline Cultura & 5 & Misticismo & 2 & Curiosidade & 12 & Indiferença & 4 \\
\hline Misticismo & 5 & Negociam & 2 & Nojo & 10 & Medo & 4 \\
\hline $\begin{array}{l}\text { Leitura de } \\
\text { mão }\end{array}$ & 5 & Pedintes & 2 & Antipatia & 8 & Nojo & 4 \\
\hline Incomodam & 4 & Sujos & 2 & Respeito & 8 & Respeito & 4 \\
\hline Barracas & 3 & $\begin{array}{l}\text { Vestimentas/ } \\
\text { adereços }\end{array}$ & 2 & Indiferença & 7 & Antipatia & 2 \\
\hline Dança/música & 3 & Errantes & 2 & Tristeza & 6 & Tristeza & 2 \\
\hline Diferentes & 3 & & & Desprezo & 5 & & \\
\hline Ladrão & 3 & & & Pânico & 4 & & \\
\hline Medo & 3 & & & Solidariedade & 3 & & \\
\hline Negociam & 3 & & & & & & \\
\hline Posses & 3 & & & & & & \\
\hline Preguiçosos & 3 & & & & & & \\
\hline Errantes & 3 & & & & & & \\
\hline
\end{tabular}

Fonte: elaborado pelos autores.

Pelas entrevistas individuais, foi possível compreender com mais clareza o que os sujeitos pensam e sentem em relação aos ciganos (conforme dados projetados na tabela 3). Nas narrativas que compuseram o corpus de dados analisado, estão presentes significados que se referem a fontes de informação e experiências de 
contato com ciganos, bem como posicionamento avaliativo em relação ao campo representacional e à dimensão afetiva. Para análise dessas informações, utilizouse o software ALCESTE, que sugeriu a sistematização dos dados com base em três classes, conforme disposição apresentada na figura 2.

Figura 2. Classificação hierárquica descendente: dendrograma das classes estáveis (cluster sentimentos negativos)

$$
\mathrm{R}=0,0
$$

\section{$R=0,33$}

\begin{tabular}{|l|c|}
\hline \multicolumn{2}{|c|}{ Classe 1 } \\
$\begin{array}{c}\text { Contato: experiências } \\
\text { e memórias }\end{array}$ \\
\hline \multicolumn{2}{|c|}{ 30 UCE - 19,87\% } \\
\hline Formas & $\chi 2$ \\
Fazenda & 16,57 \\
Interessante & 15,81 \\
Animais & 12,35 \\
Avô & 12,35 \\
Meu & 10,83 \\
Sociedade & 9,64 \\
Cabeça & 7,84 \\
Atenção & 7,84 \\
Ruas & 5,23 \\
Histórias & 5,23 \\
\hline
\end{tabular}

\begin{tabular}{|l|c|}
\hline \multicolumn{2}{|c|}{ Classe 3 } \\
Sentimentos e tomadas \\
de posição \\
\hline \multicolumn{2}{|c|}{ 76 UCE - 50,33\% } \\
\hline Formas & $\mathbf{2}$ \\
Liberdade & 11,71 \\
Modo de vida & 11,31 \\
Sinto & 9,15 \\
Ser & 8,90 \\
Vivem & 7,81 \\
Acho & 7,26 \\
Positivo & 7,24 \\
Certo & 7,24 \\
Estilo & 6,74 \\
Desconfiança & 6,17 \\
\hline
\end{tabular}

\begin{tabular}{|l|c|}
\hline \multicolumn{2}{|c|}{ Classe 2 } \\
Estereótipos \\
\hline \multicolumn{2}{|c|}{ 45 UCE - 29,80\% } \\
\hline Formas & \\
Mulher cigana & 31,15 \\
Acampamento & 26,32 \\
Colorido & 25,23 \\
Homem cigano & 22,51 \\
Imagino & 20,06 \\
Barracas & 20,06 \\
Cabelo & 12,90 \\
Ler mão & 12,90 \\
Chapéu & 12,18 \\
Dente de ouro & 12,18 \\
\hline
\end{tabular}

Fonte: elaborado pelos autores.

A classe 1, "Contato: experiências e memórias", refere-se ao conjunto de significados relacionados às experiências de contato dos participantes com o objeto de representação, nas raras situações em que estiveram envolvidos ou relativas a histórias contadas por seus familiares. Sobre o tipo de relação estabelecida com ciganos e ciganas, é importante ressaltar que a maioria dos participantes mencionou que apenas tiveram contatos rápidos e superficiais, geralmente quando abordados na rua por ciganas que ofereciam a leitura de 
mão. A maioria dos relatos sobre experiências se apoiam em "histórias contadas", reforçando estereótipos negativos, tais como "traiçoeiros", "sujos", "negociantes" e "espertalhões".

Elementos como "fazenda", "animais", "avô" e "histórias" remontam a memórias de infância, em que eram narrados casos de passagens de caravanas ciganas pela localidade de moradia e de barganha de animais entre membros da família do participante e os ciganos: "Eu tive contato e ouvi 'histórias' a respeito de ciganos. Às vezes, meu pai tomava uma pernada dos ciganos, mas isso era inabalável, até porque houve boas trocas também”. Ainda nesta primeira classe, foram frequentes as comparaçôes entre os modos de vida cigano e não cigano, $o$ que poderia indicar uma tentativa de elaboração do objeto, cujo conhecimento associado é mediado por significados de transmissão, como ilustrado na UCE a seguir: "O cigano representa para o capitalismo, para nossa sociedade, o que exclui. O que exclui nos dá nojo, nós estamos acostumados com o que é limpo. Essa imagem, eu tenho de vê-los quando era criança”.

Ligada à classe 1 com força relativa $(\mathrm{R}=0,33)$, a classe 3 ("Sentimentos e tomadas de posição") retrata o posicionamento avaliativo em relação ao modo de vida cigano, sendo recorrentes elementos como "liberdade", "estilo" e "modo de vida", que são considerados "positivos" pelos participantes: "Algo positivo em relação ao estilo de vida dos ciganos, essa coisa da liberdade, mas não sei até que ponto eles são livres". Outra dimensão importante dessa classe é o posicionamento afetivo, marcado, principalmente, por "desconfiança": "Tenho muita desconfiança porque é o desconhecido, tem essa coisa de misticismo".

O medo e o receio foram os sentimentos mais destacados pelos entrevistados, que justificaram tal posicionamento em razão da imagem dos ciganos como agentes de agressões físicas, de serem ladrões e rogadores de pragas: "Medo, medo de me roubarem. É um grupo de pessoas que eu não conheço, portanto, medo". Sentimentos como raiva, pena, pavor e aversão também foram mencionados, além de nojo, que era frequentemente associado à ideia dos ciganos como sujos e sem higiene.

Com a função de compor um campo de significação para que os indivíduos possam lidar com os diferentes objetos sociais, os estereótipos (classe 2) associam-se às memórias e aos afetos relacionados aos ciganos. Especialmente a partir de elementos compartilhados em consonância com o pensamento social hegemônico, o raro contato com os ciganos (“imagino' que seja assim”) se reflete em um conjunto de dados mais estereotípico, conforme termos mais significativos destacados nesta classe: "mulher cigana", "acampamento", "colorido", "homem 
cigano", "barracas", “cabelo”, "ler mão”, "chapéu” e "dente de ouro". O trabalho de elaboração do "ser cigano" baseado em tais elementos pode ser verificado nas UCE a seguir:

Aquelas mulheres que ficam pedindo para ler mão na rua, no transporte público, nos terminais, nas ruas e em acampamentos. Elas vestem saião, aquelas saias coloridas, estão sempre segurando uma criança no colo. Os homens são magros, com dente bem feio.

Quando se fala em ciganos, penso em: nômade, sem-terra, colorido, homens armados, dente de ouro, mulher cigana enfeitada, barracas, crianças, homem cigano com chapéu, com arma, bigode, calça "jeans" (Entrevistado).

Embora não se possa falar de um processo de ressignificação social do objeto "ciganos" para os entrevistados, é importante esclarecer que a identificação dos sujeitos junto ao cluster negativos não é uma condição exclusiva ou permanente, posto que as representações sociais estão sujeitas a modificações a partir de novas experiências e, portanto, de novas tomadas de posição por parte dos indivíduos.

\section{DISCUSSÃO}

O conjunto de dados obtido, especialmente os resultados referentes ao segundo estudo, permite discutir que, ainda que tenha sido evidenciada a existência de uma representação social sobre os grupos ciganos composta, majoritariamente, por elementos de cunho negativo, as ambiguidades e as contradições estão sempre presentes. O próprio Moscovici (2009), ao refletir sobre as relações entre os grupos hegemônicos e minoritários, discute as categorias opostas que se fazem presentes ao longo da história, por meio de themata.

O primeiro themata seria o do "puro e impuro", como evidenciado nos resultados ao serem associados aos ciganos significados como "sujos", despertando "nojo" e "aversão" nos não ciganos. O segundo themata é referente aos estigmas: por um lado positivos, em elementos como "danças", "música" e "colorido", que remetem ao gosto por festas e ao talento musical cigano e que podem despertar sentimentos de "respeito" e "curiosidade" para com essa "cultura diferente"; e, por outro lado, aos grupos ciganos é dirigido um estigma negativo que os relaciona à criminalidade, percebendo-os como "ladrões", que "enganam" e "incomodam", despertando sentimentos de "medo" e "insegurança". Outro themata característico da representação social dos ciganos pela maioria não cigana é o de "sedentário-nômade", em que o nomadismo pode ser visto como algo positivo, por exemplo, associado à prática de uma profissão, como a música (Moscovici, 2009), ou a uma "cultura de liberdade" (Souza, Bonomo, Livramento, Brasil, \& 
Canal, 2009), mas são também associados à imagem negativa de mendicância e pobreza, provocando sentimentos similares aos mencionados para os estigmas. Finalmente, um último themata característico das relações maioria-minoria é o da proibição do contato, a separação, a rejeição da minoria.

Em nossa tentativa cotidiana de compreender a realidade social, (re) produzindo representações sociais que nos auxiliem na orientação e justificação de nossas práticas e na demarcação de fronteiras entre "nós" e os "outros" (Jodelet, 2001), tendemos a afastar, a excluir e a temer aquelas categorias sociais consideradas como estranhas, distantes e desconhecidas (Jodelet, 2005), o que acaba por reforçar práticas discriminatórias, relegando a esse "outro" um lugar marginal na sociedade. Nesse movimento de demarcar as diferenças e as fronteiras identitárias, principalmente no que diz respeito a grupos étnicos como os ciganos, tendemos a naturalizar certas características, entendendo-as como imutáveis e intrínsecas (Cabecinhas \& Amâncio, 2004; Wagner, Holz \& Kashima, 2009), de modo a essencializar algumas categorias sociais, fortalecendo ainda mais a rigidez das fronteiras que separam determinados grupos (Wagner et al., 2009). Esse processo de distanciamento entre minorias e maiorias pode levar a uma acentuação do preconceito e da exclusão de tal forma que chegue até mesmo a um distanciamento dessa minoria da categoria de humano, como, por vezes, acontece no caso dos ciganos, seja por ontologização (Pérez, Moscovici, \& Chulvi, 2002) ou por infra-humanização (Marcu \& Chryssochoou, 2005).

Tendo em vista esses fenômenos, quando falamos em pluralidade cultural, em respeito pelos diversos "outros", é necessário ir além da mera tolerância do diferente, visto que apenas a tolerância pode manter a ideia de superioridade de determinados grupos e não questionar diferentes formas de dominação social. Nesse sentido, faz-se necessário haver de fato diálogos, trocas e esforços no intuito de compreender melhor o "outro" por ele mesmo, de forma que seja possível haver respeito e valorização das diferentes formas de ser e estar no mundo, dos diferentes grupos e culturas.

\section{CONSIDERAÇÕES FINAIS}

Com base no desenvolvimento da pesquisa, foi possível verificar correspondência no que concerne às representaçôes sociais hegemônicas acerca dos ciganos, geralmente apoiadas em elementos negativos, e os resultados encontrados nos estudos realizados. Ao adotar a abordagem não consensual das representações sociais, visando a conhecer as modulações individuais que compõem o conjunto de significados associados ao objeto social em estudo, foi possível demonstrar a existência de diferentes posicionamentos em relação ao campo representacional de ciganos. 
Principalmente no que se refere aos resultados do cluster sentimentos negativos, constatamos que o distanciamento em relação aos ciganos se manifesta concretamente nas relações sociais. A desconfiança, insegurança e mal-estar como os sentimentos negativos mais citados, as generalizaçóes dos significados associados aos membros dos grupos ciganos, marcadamente sustentados em estereótipos de valoração negativa, ratificam essa condição de discriminação social. Os desafios em lidar com o "outro", com grupos considerados "diferentes", de vencer o preconceito que geralmente regula a relação entre grupos hegemônicos e minoritários, certamente envolvem processos de ressignificação das representaçôes sociais envolvidas. Nesse sentido, um dos desafios da "causa cigana" é justamente a promoção de processos que promovam a desmistificação dessa imagem negativa historicamente construída e reforçada.

Por fim, parece ser importante ressaltar ainda que as estratégias metodológicas utilizadas nesta pesquisa não permitiram apenas constatar o processo de formação do imaginário dos participantes acerca dos ciganos, mas atuou, em alguns casos, também como estímulo à reflexão dos sujeitos acerca de seu próprio posicionamento em relação aos ciganos. Esperamos, portanto, que este trabalho possa contribuir para a discussão acerca da produção da imagem negativa associada aos grupos étnicos ciganos, que estigmatiza e promove processos de segregação social, bem como desperte o interesse de outros pesquisadores que identifiquem no fenômeno apresentado um campo de estudo social e cientificamente relevante. 


\section{REFERÊNCIAS}

Acton, T. H. \& Mundy, G. (1997). Romani culture and gypsy identity. Hertfordshire: University of Hertfordshire Press.

Alexandre, J. D. (2003). Ciganos, senhores e galhardós: um estudo sobre percepçôes $e$ avaliações intra $e$ intergrupais na infância. (Dissertação de Mestrado). Departamento de Psicologia Social e das Organizações do Instituto Superior de Ciências do Trabalho e da Empresa, Lisboa.

Araújo, M. C. (2008). A teoria das representações sociais e a pesquisa antropológica. Revista Hospitalidade, 2, 98-119.

Arruda, A. M. S. (2009a). Meandros da teoria: a dimensão afetiva das representaçōes sociais. In A. M. O. Almeida \& D. Jodelet (Orgs.), Representaçôes sociais: interdisciplinaridade e diversidade de paradigmas. (pp. 35-50). Brasília: Thesaurus.

Arruda, A. M. S. (2009b). Teoria das representações sociais e ciências sociais: trânsito e atravessamentos. Sociedade e Estado, 24(3), 739-766.

Arruda, A. M. S. \& Pombo-de-Barros, C. F. (2010). Afetos e representações sociais: contribuições de um diálogo transdisciplinar. Psicologia: Teoria $e$ Pesquisa, 2 (26), 351-360.

Cabecinhas, R. \& Amâncio, L. (2004). Dominação e exclusão: representações sociais sobre minorias raciais e étnicas. In Actas, 5 Congresso Português de Sociologia: sociedades contemporâneas: reflexividade e acção, Braga. Braga: Universidade do Minho.

Camargo, B. V. (2005). Alceste: um programa informático de análise quantitativa de dados textuais. In A. S. P. Moreira (Org.), Perspectivas teórico-metodológicas em representaçôes sociais. (pp. 511-540). João Pessoa: UFPB.

Campos, P. H. F. \& Rouquette, M. L. (2003). Abordagem estrutural e componente afetivo das representações sociais. Psicologia: Reflexão e Crítica, 16(3), 435-445.

Doise, W. (1992). L'ancrage dans les études sur les représentations socials. Bulletin de Psychologie, 45, 189-195.

Doise, W., Clemence, A. \& Lorenzi-Cioldi, F. (1995). Rappresentazioni sociali e analisi dei dati. Bologna: Il Mulino. 
Ferrari, F. (2002). Um olhar oblíquo: contribuiçôes para o imaginário ocidental sobre o cigano. (Dissertação de Mestrado). Departamento de Antropologia Social, Universidade de São Paulo, São Paulo.

Freire Filho, J. (2004). Mídia, estereótipo e representação das minorias. ECOPÓS, 7(7), 45-71.

Guareschi, P. \& Jovchelovitch, S. (2008). Introdução. In Textos em representações sociais. (pp.17-25). Petrópolis: Vozes.

Jodelet, D. (2005). Loucuras e representaçôes sociais. Petrópolis: Vozes.

Jodelet, D. (2001). Representações sociais: um domínio em expansão. In D. Jodelet (Org.), As representaçôes sociais. (pp. 17-44). Rio de Janeiro: Ed. UERJ.

Lebart, L., Morineau, A., Becue, M., \& Haeusler, L. (1994). SPAD-T - Manuel de l'utilisateur. Saint-Mondé: Cisia - Centre International de Statistique et d'Informatique appliquées.

Marcu, A \& Chryssochoou, X. (2005). Exclusion or ethnic groups from the realm of humanity: prejudice against the Gypsies in Britain and in Romania. Psicología Política, 30, 41-56.

Marková, I. (2003). Dialogical triads and three-component processes. In Dialogicality and social representations: the dynamics of mind. (pp. 147-176). Cambridge: Cambridge University Press.

Marková, I. (2006). Dialogicidade e representaçôes sociais: as dinâmicas da mente. Petrópolis: Vozes.

Miranda, F. P. F. (2011, novembro). Ciganos no documentário brasileiro: imagens do passado refletidas no presente. Revista Panorama, 2, 29-42. Recuperado a partir de http://seer.pucgoias.edu.br/index.php/panorama/ article/download/1862/1162

Moonen, F. (2008). Anticiganismo na Europa. Recife: Núcleo de Estudos Ciganos.

Moonen, F. (2011). Anticiganismo: os ciganos na Europa e no Brasil. (3a ed. rev. atual.). Recife: Núcleo de Estudos Ciganos.

Moscovici, S. (1961). La Psychanalyse, son image et son public. Paris: Press Universitary de France.

Moscovici, S. (1978). A representação social e psicanálise. Rio de Janeiro: Zahar. 
Moscovici, S. (1992, 3 ottobre). Themata e rappresentazioni sociali. In Conferenza Internazionale sulle Rappresentazioni Sociali, Ravello. Recuperado a partir de http://www.europhd.net/bibliographic-items/conference-presentations/ themata-e-rappresentazioni-sociali

Moscovici, S. (2003). Representaçôes sociais: investigaçôes em psicologia social. Petrópolis: Vozes.

Moscovici, S. (2009). Preconceito e representações sociais. In A. M. O. Almeida \& D. Jodelet (Orgs.), Representaçôes sociais: interdisciplinaridade e diversidade de paradigmas. (pp. 17-34). Brasília: Thesaurus.

Oliveira, D.C., Gomes, A. M. T., \& Marques, S. C. (2005). Análise estatística de dados textuais na pesquisa das representaçóes sociais: alguns princípios e uma aplicação ao campo da saúde. In S. S. S. Menin \& A. M. Shimizu (Orgs.), Experiência e representação social: questôes teóricas e metodológicas. (pp. 23-56). São Paulo: Casa do Psicólogo.

Pereira, C., Torres, A. R. R. \& Almeida, S. T. (2003). Um estudo do preconceito na perspectiva das representações sociais: análise da influência de um discurso justificador da discriminação no preconceito racial. Psicologia: Reflexão $e$ Critica, 16(1), 95-107.

Pérez, J. A., Moscovici, S., \& Chulvi, B. (2002). Natura y cultura como principio de clasificación social: anclaje de representaciones sociales sobre minorías étnicas. Revista de Psicología Social, 17(1), 51-67.

Reinert, M. (1990). Alceste, une methodologie d'analyse des donnees textuelles et une application: Aurelia de Gerard de Nerval. Bulletin de Methodologie Sociologique, 26, 24-54.

Rezende, D. F. A. (2000). Transnacionalismo e etnicidade: a construção simbólica do Romanesthàn. (Dissertação de Mestrado). Departamento de Sociologia, Faculdade de Filosofia e Ciências Humanas, Universidade Federal de Minas Gerais, Belo Horizonte.

Sá, C. P. (1998). A construção do objeto de pesquisa em representaçôes sociais. Rio de Janeiro: Ed. UERJ.

Sibar, L. M. L. (2012). Identidade, alteridade e resistência dos ciganos brasileiros. (Dissertação de Mestrado). Universidade Estadual Paulista, Faculdade de Filosofia e Ciências de Marília, Marília. Recuperado a partir de https:// repositorio.unesp.br/handle/11449/88717 
Souza, L. (2004). Processos de categorização e identidade: solidariedade, exclusão e violência. In L. Souza \& Z. A. Trindade (Orgs.), Violência e exclusão: convivendo com paradoxos. (pp. 57-74). São Paulo: Casa do Psicólogo.

Souza, L., Bonomo, M., Livramento, A. M., Brasil, J. A., \& Canal, F. D. (2009). Processos identitários entre ciganos: da exclusão a uma cultura de liberdade. Liberabit, 15, 39-47.

Teixeira, R. C. (2008). História dos ciganos no Brasil. Recife: NEC.

Wagner, W, Holtz, P., \& Kashima, Y. (2009). Construction and descronstruction of essence in representating social groups: identity projects, stereotyping and racism, Journal for the Theory of Social Behaviour, 39(3), 363-383. 